\title{
A model sea urchin spicule matrix protein self-associates to form mineral-modifying hydrogels. Supporting Information.
}

\author{
Gaurav Jain, ${ }^{1 \uparrow}$ Martin Pendola, ${ }^{1 \pi}$ Ashit Rao, ${ }^{2}$ Helmut Cölfen, ${ }^{2}$ and John Spencer \\ Evans $^{1^{*}}$
}

${ }^{1}$ Laboratory for Chemical Physics, Center for Skeletal and Craniofacial Biology, New York University, 345 E. 24th Street, NY, NY, 10010 USA.

${ }^{2}$ Department of Chemistry, Physical Chemistry, Universität Konstanz, Universitätstrasse 10, Konstanz D78457, Germany.

*To whom correspondence should be addressed: John Spencer Evans, Laboratory for Chemical Physics, Center for Skeletal Biology, New York University College of Dentistry, 345 E. 24th Street, New York, NY, 10010. Tel.: (347) 753-1955 Fax: (212) 995-4087. Email: jse1@nyu.edu

This research was supported by the U.S. Army Research Office, Division of Life Sciences, under awards W911NF-12-1-0255 and W911NF-16-1-0262. 


\section{TABLE OF CONTENTS}

I. Primary sequence alignments of $S$. purpuatus spicule matrix proteins SpSM30, SpSM30B, SpSM30C (Figure S1)

II. Recombinant expression and SDS-PAGE analyses of bacterial $\mathrm{rSpSM} 30 \mathrm{~B} / \mathrm{C}-\mathrm{N}$ and insect cell rSpSM30B/C-G variant mixture (Figures S2, S3, Table S1).

III. Glycosylation mapping of tag-free purified rSpSM30B/C-G insect cell-expressed variant mixture (Table S2, Figure S4).

IV. Potentiometric Ca(II) titrations of rSpSM30B/C-G (Figure S5, Table S3).

I. Primary sequence alignments of $S$. purpuatus spicule matrix proteins SpSM30, SpSM30B, SpSM30C.

\begin{tabular}{|c|c|c|c|c|c|}
\hline & 1 & & & & 50 \\
\hline SpSM30B & QLPGAGGPVL & PGGGPTIGPV I & NPDPTRTEA CAKFI & WVQEGN & YLFDSGAF \\
\hline SpSM30 & QLPGAGGPVL & PGGGPTIGPV I & NPDPTRTEV CAKFI & WVQEGN & YLFDSGAF \\
\hline SpSM30C & QLPGAGGPVL & PGGGPTIGPV I & NPDPTRTEV CAKFI & WVQEGN & YLFDSGAF \\
\hline SpSM30B & $\begin{array}{l}\text { 5I } \\
\text { LRQVAASRPV }\end{array}$ & VVNN E NGLFQ & 2 AAANMYCGQM & HPNASLVTVN & $\begin{array}{l}100 \\
\text { SLAENNFLYE }\end{array}$ \\
\hline SpSM30 & LRQVAASRPV & VVNNQDGLFQ & AAANMYCGQM & HPNASLVTVN & SLEENNFLYE \\
\hline SpSM30C & LRQVAASRPV & VVNNQDGLFQ & AAANMYCGQM & HPNASLVTVN & SLAENNFLYE \\
\hline SpSM30B & $\begin{array}{l}\text { I01 } \\
\text { WAVRMMVEPE }\end{array}$ & PVWIGLHAGP & MGQWQWYSGE & PVTYTNWERM & TAPMAEPGLG \\
\hline SpSM30 & WAVRMMIEPE & PVWIGLHAGP & TGQWQWYSGE & PVTYTNWERM & I TPP IAEPGLG \\
\hline SpSM30C & WAVRMMVEPE & PVWIGLHAGP & TG LWQWYSGE & PVTYTNWERM & I TAP I AEPGLG \\
\hline SpSM30B & $\begin{array}{l}\text { I5I } \\
\text { AMIFDADIIA }\end{array}$ & QMFNNQVEIT & PQWVPEQAIN & DRHALICEYH & PSGMTAAA $*$ *A \\
\hline SpSM30 & AMIFDADIIA & QMFNNQVEIT & PQWVPEQAIN & DRHALICEYH & PSGMTAAAAAP \\
\hline SpSM30C & AMIFDADIIA & QMFNNQVEIT & PQWVPEQAIN & DRHALICEYH & $\begin{array}{r}\text { PSGMTAAAAAP } \\
200\end{array}$ \\
\hline SpSM30B & $\stackrel{199}{\text { TNAPTFPPMA }}$ & TAPPMAATTR & GPVMFQNNPR & NLVNSLTGGR & $\begin{array}{l}248 \\
\text { FGGSLLHEIP }\end{array}$ \\
\hline SpSM30 & TNAPTFPPMT & TAPPMAATTR & GPVMFQNNPR & NLVNSLTGGR & FGGSLLHEIP \\
\hline SpSM30C & $\underset{201}{\text { TNAPTFPPMT }}$ & TAPPMAATTR & GPVMFQNNPR & NLVNSLTGGR & FGGSLLHEIP \\
\hline SpSM30B & $\begin{array}{l}249 \\
\text { RRQRMRPSNY }\end{array}$ & RKNPYFGIQP & & & \\
\hline SpSM30 & RRQRMRPSNY & RKNPYFGIQP & & & \\
\hline SpSM30C & $\underset{251}{\text { RRQRMRPSNY }}$ & $\begin{array}{r}\text { RKNPYFGIQP } \\
270\end{array}$ & & & \\
\hline
\end{tabular}

Figure S1. CLUSTAL O (1.2.1) multiple sequence alignment of $S$. purpuratus sea urchin embryo spicule matrix proteins SpSM30B (268 AA), SpSM30 (aka SpSM30B/C, 270 AA), and SpSM30C (270 AA). Sequences obtained from Reference 2. Red indicates substitutions. Note that SpSM30B has a 2-AA deletion (A198, A199). Courtesy of Prof. Derk Joester, Northwestern University. 
II. Recombinant expression and analyses of bacterial $\mathrm{rSpSM30B/C-N}$ and insect cell rSpSM30B/C-G variant mixture.

gp67-H6-TEV-rSpSM30B/C (rSpSM30B/C-G)

gP67-HHHHHHENLYFQ | GQLPGAGGPVLPGGGPTIGPVNPDPTRTEVCAKFWVQEGNSCY LFDSGAFLRQVAASRPVVVNNQDGLFQAAANMYCGQMHPNASLVTVNSLEENNFLYEWAV RMMIEPEPVWIGLHAGPTGQWQWYSGEPVTYTNWERMTPPIAEPGLGAMIFDADIIAQMFN NQVEITPQWVPEQAINDRHALICEYHPSGMTAAAAAPTNAPTFPPMTTAPPMAATTRGPVM FQNNPRNLVNSLTGGRFGGSLLHEIPRRQRMRPSNYRKNPYFGIQP

\section{Trx-H6-TEV-rSpSM30B/C (rSpSM30B/C-N)}

TrX-HHHHHHENLYFQ | GQLPGAGGPVLPGGGPTIGPVNPDPTRTEVCAKFWVQEGNSCY LFDSGAFLRQVAASRPVVVNNQDGLFQAAANMYCGQMHPNASLVTVNSLEENNFLYEWAV RMMIEPEPVWIGLHAGPTGQWQWYSGEPVTYTNWERMTPPIAEPGLGAMIFDADIIAQMFN NQVEITPQWVPEQAINDRHALICEYHPSGMTAAAAAPTNAPTFPPMTTAPPMAATTRGPVM FQNNPRNLVNSLTGGRFGGSLLHEIPRRQRMRPSNYRKNPYFGIQP

Figure S2: rSpSM30B/C-N (bacterial expression, E. coli) and $\mathrm{rSpSM} 30 \mathrm{~B} / \mathrm{C}-\mathrm{G}$ (insect cell expression, Sf9) subclone sequences (Trx sequence in green, gp67 envelope glycoprotein secretion signal sequence in red, $\mathrm{His}_{6}$ tag in blue, TEV cleavage site in orange, vertical line denotes site of cleavage). Postcleavage forms of both $\mathrm{rSpSM} 30 \mathrm{~B} / \mathrm{C}$ proteins begins with Gly in the sequence above (i.e., total sequence length of both recombinants are $271 \mathrm{AA}$, with G1 at the $\mathrm{N}$-terminus and P271 at the C-terminus).

Figure S3: 4-20\% gradient SDSPAGE gel analysis (Coomassie Blue staining) of tag-free, purified recombinant proteins. (A) $\mathrm{rSpSM} 30 \mathrm{~B} / \mathrm{C}-\mathrm{N}$. Lane $\mathrm{M}$ : MW standards (in $\mathrm{kDa}$ ), Lane 2: $2 \mu \mathrm{g}$ rSpSM30B/C-N. rSpSM30B/C-G. Lane M: MW kDa standards (in $\mathrm{kDa}$ ). Lane 2: 1.4 $\mu \mathrm{g}$ rSpSM30B/C-G ("ensemble" 94 denotes multiple bands reflecting unglycosylated and glycosylated protein variants; "dimers" denotes presence of 36 higher MW, weakly staining species corresponding to $2 \mathrm{x}$ MW 26 of the primary bands in "ensemble"). Lane 3: $1 \mu \mathrm{g}$ BSA.

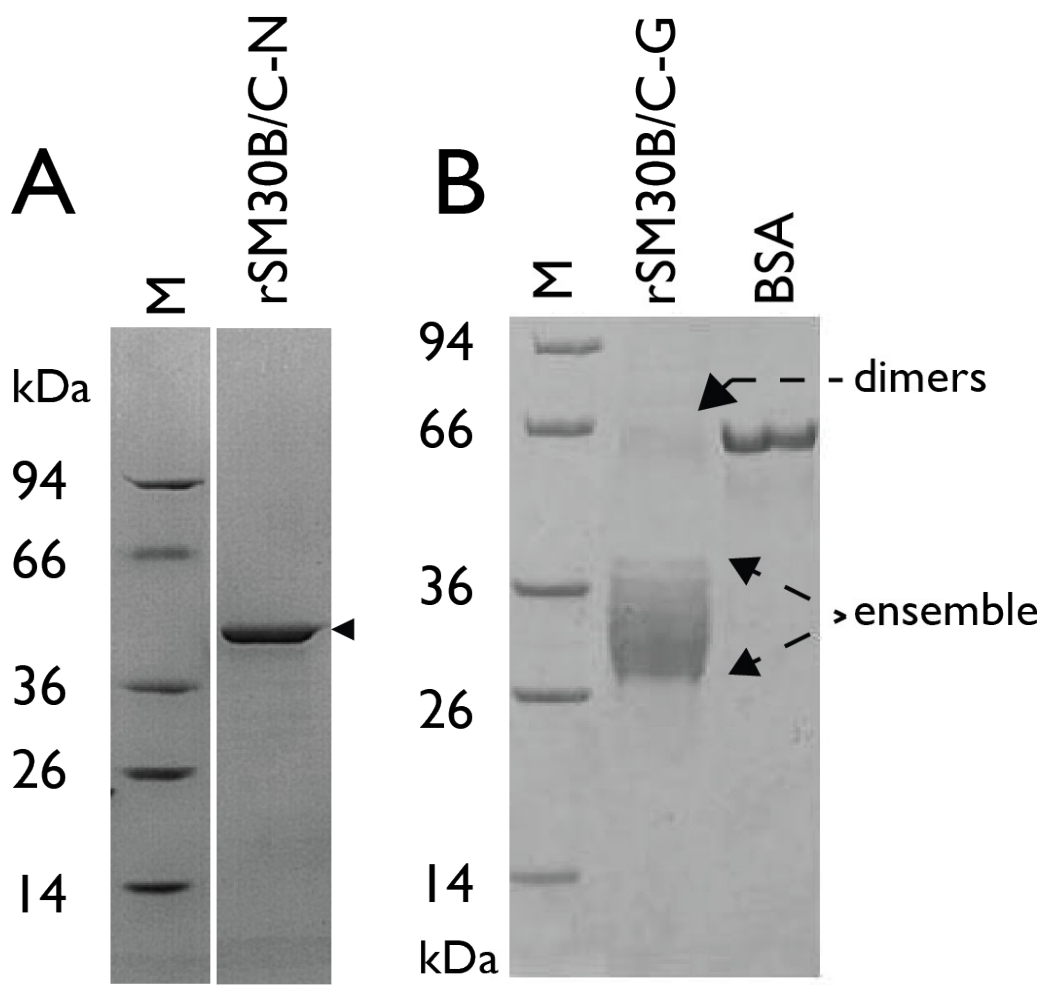


Table S1 Representative N-terminal sequencing first cycle chromatograms of tag-free, purified rSpSM30B/C-G ensemble mixture.

\begin{tabular}{|l|c|c|c|c|c|c|c|c|}
\hline & Cycle 1 & Cycle 2 & Cycle 3 & Cycle 4 & Cycle 5 & Cycle 6 & Cycle 7 & Cycle 8 \\
\hline Theoretical & $\mathrm{G}$ & $\mathrm{Q}$ & $\mathrm{L}$ & $\mathrm{P}$ & $\mathrm{G}$ & $\mathrm{A}$ & $\mathrm{G}$ & $\mathrm{G}$ \\
\hline Ensemble & $\mathrm{G}$ & $\mathrm{Q}$ & $\mathrm{L}$ & $\mathrm{P}$ & $\mathrm{G}$ & $\mathrm{A}$ & $\mathrm{G}$ & $\mathrm{G}$ \\
\hline
\end{tabular}

The mixture was subjected to Edman degradation using a Shimadzu PPSQ-33A N-terminal sequencer. Eight cycles were performed and parallel runs were conducted using a blank buffer sample and a recombinant human parathyroid hormone (rhPTH) sample for comparison (data not shown).

\section{Glycosylation mapping of tag-free purified insect cell-expressed rSpSM30B/C-G variant mixture.}

Table S2: MALDI-TOF-MS adducts, monosaccharide matching, and corresponding oligosaccharide structures for $\mathrm{rSpSM} 30 \mathrm{~B} / \mathrm{C}-\mathrm{G}$ protein ensemble.

\begin{tabular}{|c|c|c|c|c|c|}
\hline $\mathbf{m} / \mathbf{z}$ & Adduct & Monosaccharide Match & $\Delta \mathrm{Da}$ & $\begin{array}{l}\text { Oligosaccharide } \\
\text { Structure }\end{array}$ & Cartoon Structure \\
\hline 914.5 & M-H & $\mathrm{NeuAcSulfHexNAc}_{2}$ & -1.219 & $\begin{array}{l}\text { Sulfated, sialylated O- } \\
\text { glycan }\end{array}$ & \\
\hline & & $\mathrm{NeuAcHexNAc}_{3}$ & 1.349 & Sialylated O-glycan & \\
\hline 1040.2 & $\mathrm{M}-\mathrm{H}$ & $\mathrm{Fuc}_{2} \mathrm{HexNAc}_{3}$ & 0.321 & Bifucosylated O-glycan & \\
\hline \multirow{3}{*}{1054.7} & \multirow{2}{*}{ M-H } & $\mathrm{SulfFucHexNAc}_{3}$ & 0.86 & $\begin{array}{l}\text { Sulfated, fucosylated } \\
\text { O-glycan }\end{array}$ & $\mathrm{s}$ \\
\hline & & HexHexNAc 3 Fuc & -1.177 & Fucosylated O-glycan & $\mathrm{O}$ \\
\hline & $\mathrm{M}+\mathrm{TFA}$ & NeuAcFucHexHexNAc & -0.069 & $\begin{array}{l}\text { Sialylated, fucosylated } \\
\text { O-glycan }\end{array}$ & \\
\hline
\end{tabular}




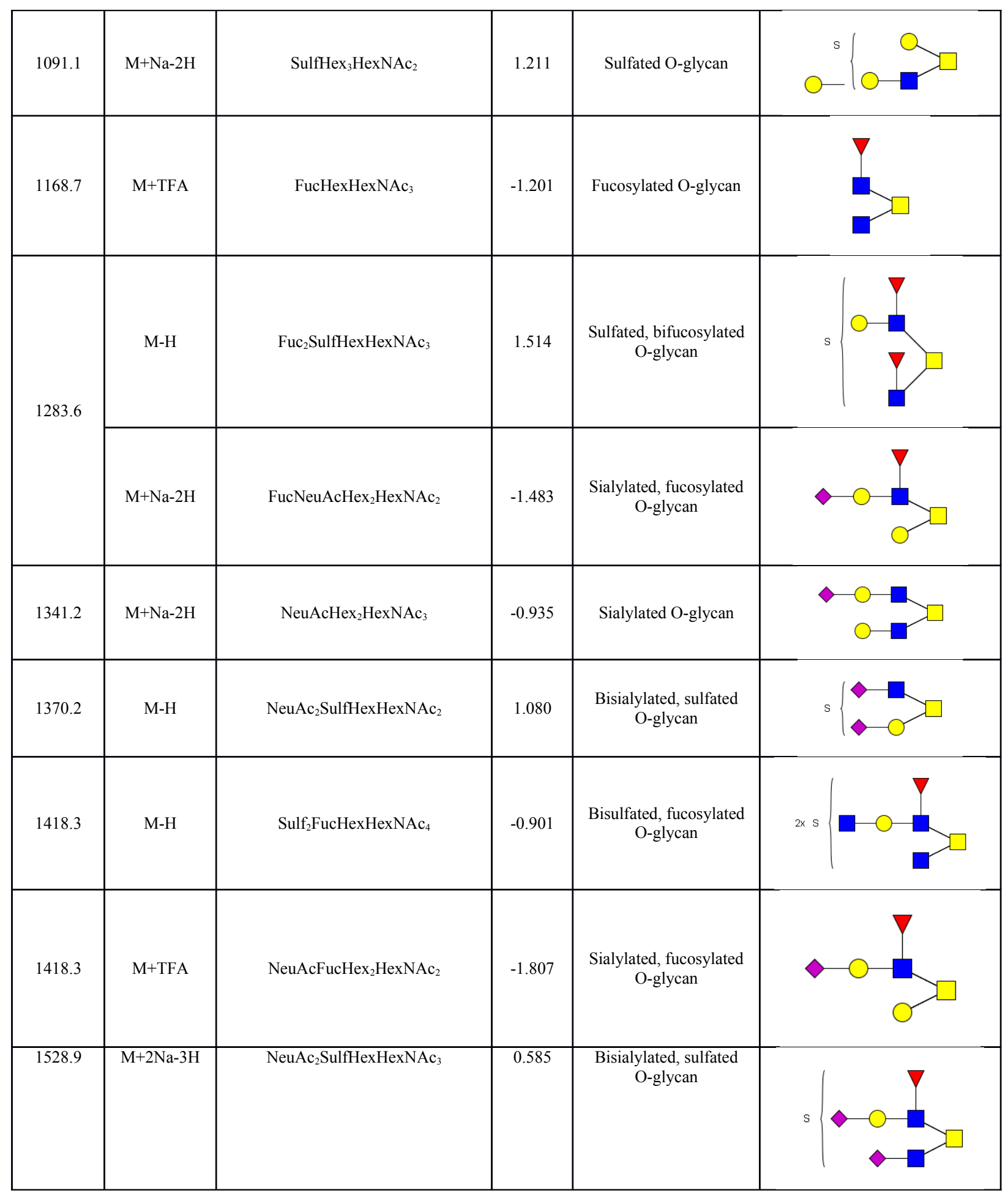




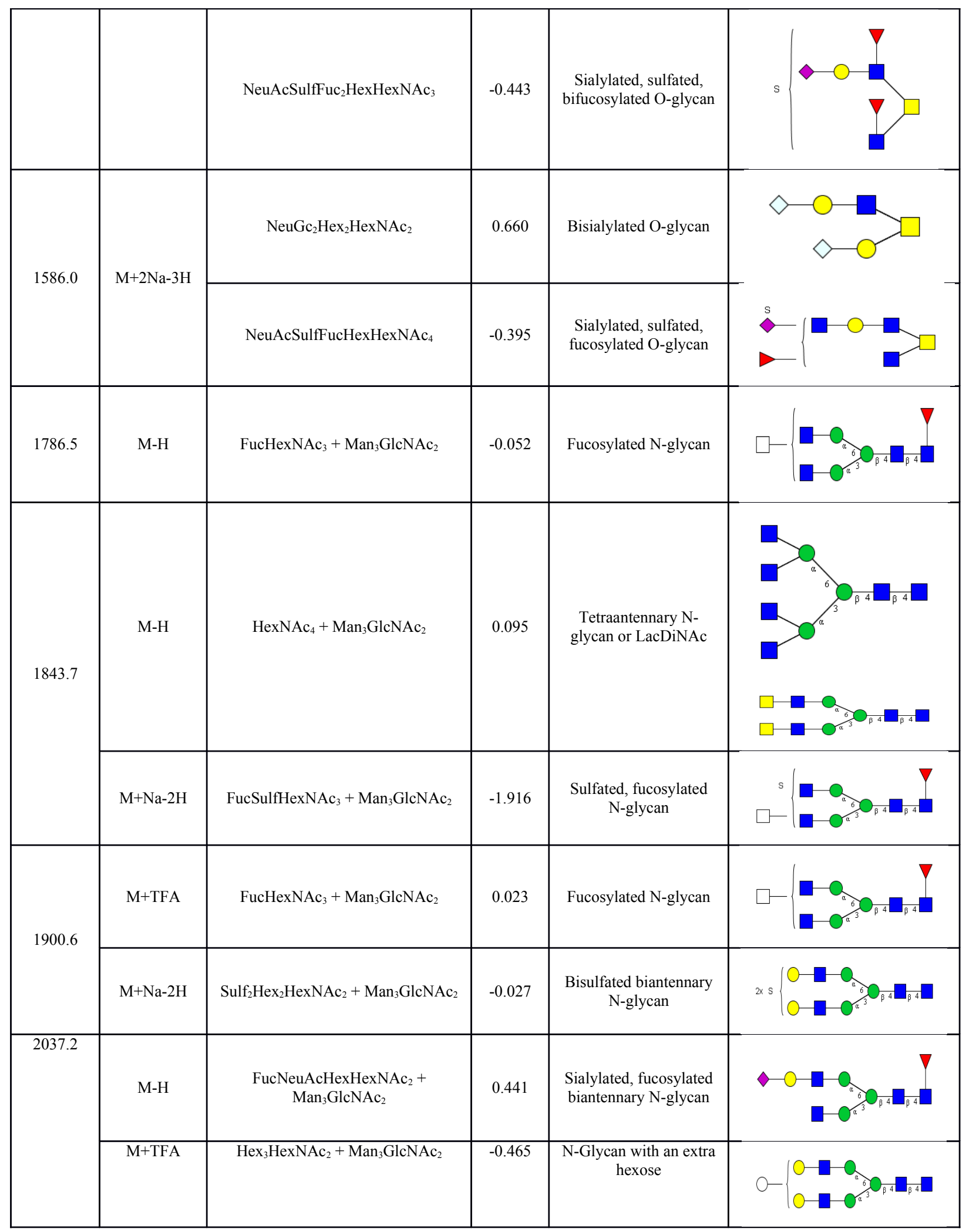




\begin{tabular}{|c|c|c|c|c|c|}
\hline & & $\mathrm{SulfHexNAc}_{4}+\mathrm{Man}_{3} \mathrm{GlcNAc}_{2}$ & -0.492 & Sulfated N-glycan & 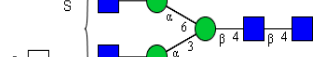 \\
\hline \multirow{3}{*}{2102.1} & \multirow{2}{*}{$\mathrm{M}+\mathrm{TFA}$} & $\begin{array}{c}\text { FucSulf }{ }_{2} \mathrm{Hex}_{2} \mathrm{HexNAc}_{2}+ \\
\mathrm{Man}_{3} \mathrm{GlcNAc}_{2}\end{array}$ & 0.369 & $\begin{array}{l}\text { Fucosylated, bisulfated, } \\
\text { biantennary N-glycan }\end{array}$ & $2 \times 8$ \\
\hline & & $\mathrm{FucHexNAc}_{4}+\mathrm{Man}_{3} \mathrm{GlcNAc}_{2}$ & -1.671 & Fucosylated N-glycan & $2 \times \square-$ \\
\hline & $\mathrm{M}+\mathrm{Na}-2 \mathrm{H}$ & $\mathrm{Sulf}_{2} \mathrm{Hex}_{2} \mathrm{HexNAc}_{3}+\mathrm{Man}_{3} \mathrm{GlcNAc}_{2}$ & -1.722 & $\begin{array}{l}\text { Bisulfated triantennary } \\
\text { N-glycan }\end{array}$ & ${ }_{2 \times s}^{\square-1}$ \\
\hline
\end{tabular}

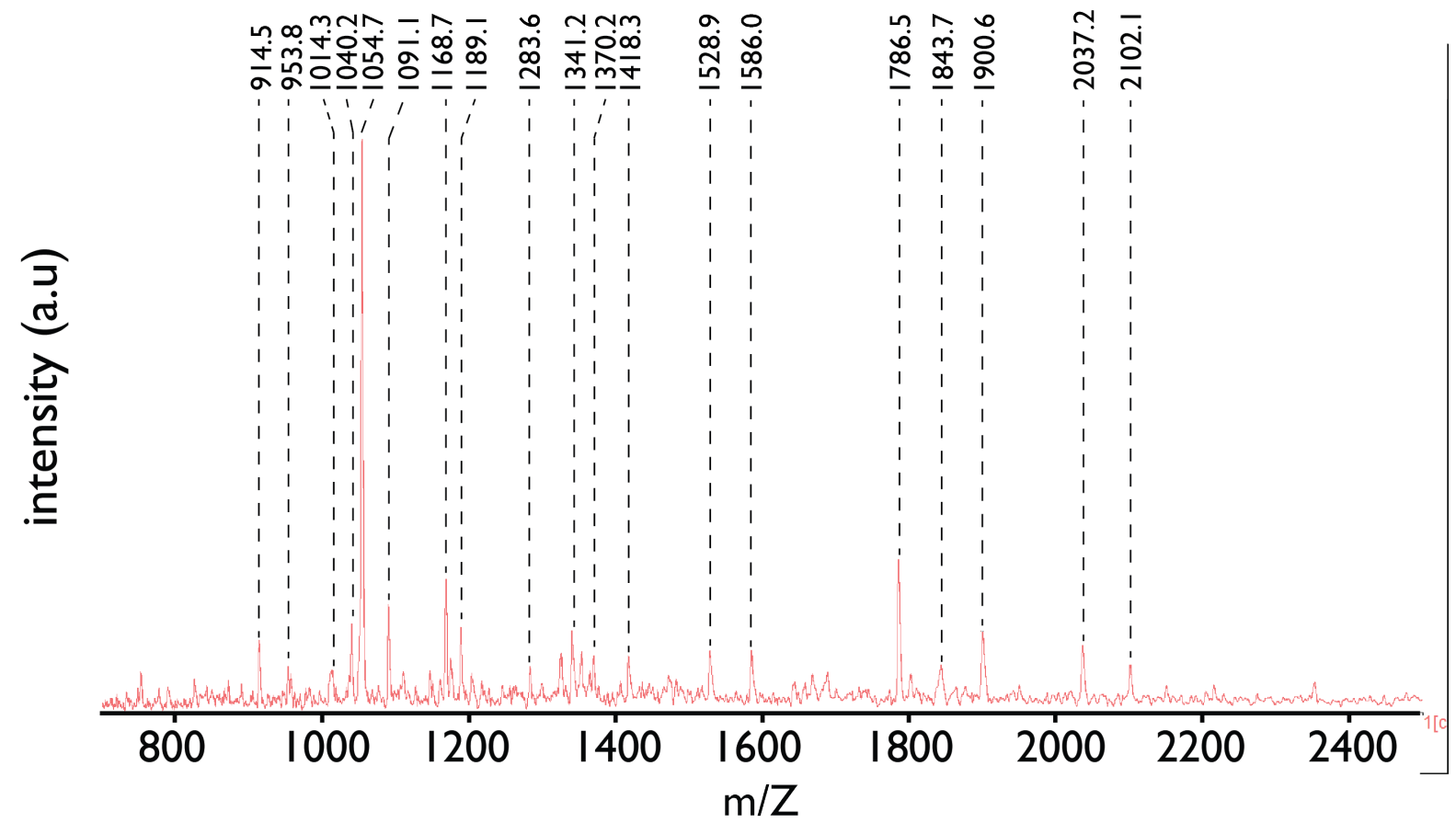

Figure S4: MALDI-TOF-MS spectra (negative ion mode) of tag-free purified rSpSM30B/C-G $\mathrm{N}$ - and O-linked oligosaccharide profile. The $\mathrm{m} / \mathrm{Z}$ values for annotated adduct species are listed in Table S2. Note that the assignments in Table S2 are tentative and may be affected by the weak intensities of the adduct species. 


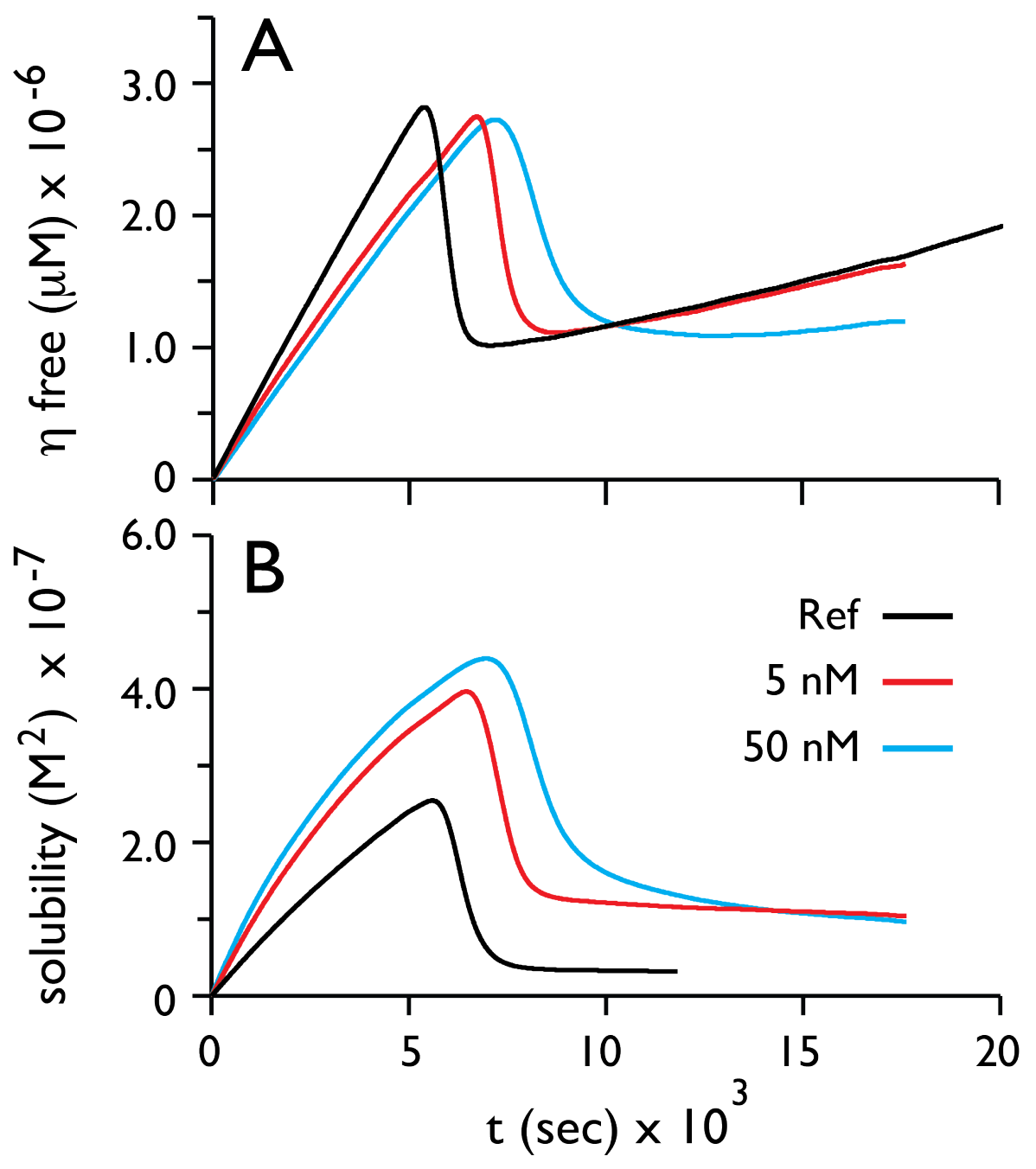

Figure S5: Development of free $\mathrm{Ca}(\mathrm{II})$ ion concentration (A) and calcium carbonate solubility product (B) in potentiometric titrations of 5 and $50 \mathrm{nM} \mathrm{rSpSM} 30 \mathrm{~B} / \mathrm{C}-\mathrm{G}$ in $10 \mathrm{mM}$ carbonate buffer, $\mathrm{pH} 9.0$ as a function of time. In each plot the reference curve refers to parallel experiments conducted in the absence of protein.

The standard potentiometric curve (A) provides information on the formation and stabilities of PNCs in solution. As free $\mathrm{Ca}^{2+}$ is added to the carbonate solution, ion complexes (i.e., PNCs) form and this is represented by the initial linear region of the titration curve. Where the measured free $\mathrm{Ca}^{2+}$ decreases upon further addition of $\mathrm{CaCl}_{2}$ (i.e., the peak region), this marks the start of solid phase nucleation (e.g., ACC) from PNCs. With respect to PNC stability, the slope of the prenucleation regime (i.e., the initial linear region) provides indirect evidence of the interaction between additive molecules and solute ion associates, leading to PNC stabilization (i.e., Slope $_{\text {Additive }}<$ Slope $_{\text {Ref }}$ ) or destabilization $\left(\right.$ Slope $_{\text {Additive }}>$ Slope $_{\text {Ref }}$ ). 
Table S3: Calcium potentiometric titration data obtained for $\mathrm{rSpSM} 30 \mathrm{~B} / \mathrm{C}-\mathrm{G}$ and reference (protein-deficient) samples.

\begin{tabular}{|l|c|c|c|}
\multicolumn{1}{|c|}{ Parameter } & Reference & \multicolumn{2}{c|}{ rSpSM30B/C-G } \\
\hline & & $5 \mathrm{nM}$ & $50 \mathrm{nM}$ \\
\hline Slope $\left(\mathrm{mol} / \mathrm{s}^{2}\right)$ & $5.28 \mathrm{E}-010$ & $4.13 \mathrm{E}-010$ & $4.03 \mathrm{E}-010$ \\
\hline Nucleation time $(\mathrm{s})$ & 5400 & 6700 & 7200 \\
\hline Solubility $\left(\mathrm{M}^{2}\right)^{*}$ & $3.17 \mathrm{E}-008$ & $1.04 \mathrm{E}-007$ & $9.67 \mathrm{E}-008$ \\
\hline
\end{tabular}

*Post-nucleation solubility

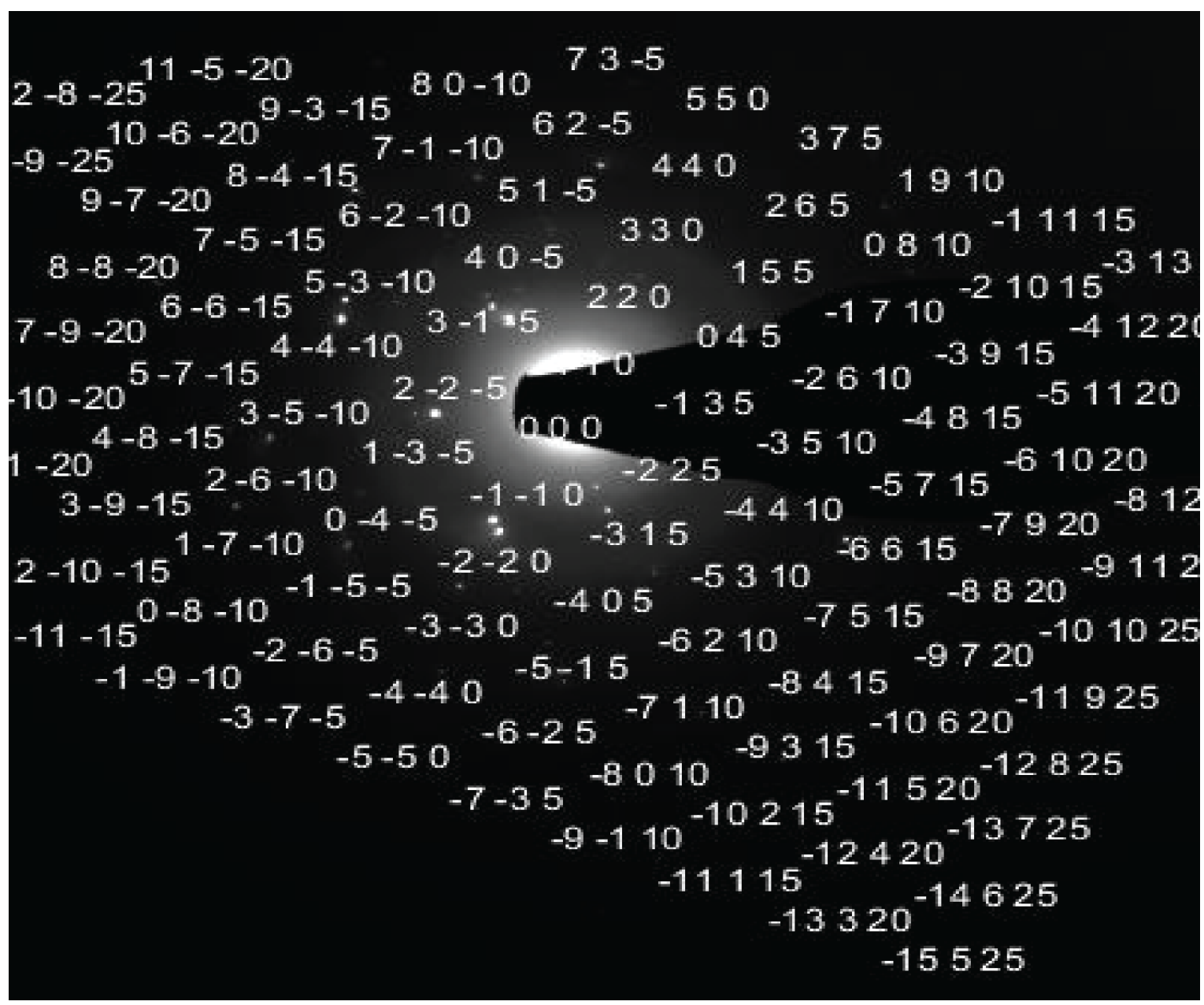

Figure S6. Selected area electron diffraction pattern obtained for mineral nanoparticle embedded within rSpSM30B/C-G protein matrix (Fig 6C). The patterns were analyzed and indexed using CrysTBox software package. 